\title{
Observations on Archivists, Librarians, and the National Union Catalog of Manuscript Collections
}

The Anglo-American Cataloging Rules have incorporated the descriptive cataloging rules used for entries in the National Union Catalog of Manuscript Collections. The relevancy of these rules and of "cataloging" itself is questioned. Experience with NUCMC should enable librarians to learn how manuscript collections are researched thereby to devise appropriate descriptive techniques. Recommendations for improving NUCMC: more extensive indexing of names (but largely eliminating them from contents note), use of broad subject headings, and addition of chronological index.

$\mathrm{T}^{\mathrm{T}}$ methodology underlying cataloging for the National Union Catalog of Manuscript Collections and of the new AngloAmerican Cataloging Rules for nonbook materials. ${ }^{1}$ It also includes recommendations for changes in the light of this criticism.

The NUCMC represents a single interphased system of national bibliographic control. This fact is of the utmost importance; it is the really important contribution of NUCMC to the methodology of bibliographic control of manuscript collections.

It has guide entries and a cumulative name, subject, and place index which refers users to the appropriate manuscript groups wherever they are. And

\footnotetext{
${ }^{1}$ Anglo-American Cataloging Rules (American Li-
} brary Association, 1967).

Mr. Berner is University Archivist in the University of Washington. This article is based on a paper given at a meeting of the Society of American Archivists in Santa Fe, October 18, 1967. this is done by a uniform method. However, this method and its implications for librarians at the repository level bear examination. The librarian normally has had little or no exposure to archival methods so he is inclined to apply methods of the librarian, particularly if they bear the imprint of the Library of Congress and of the American Library Association.

These methods have been developed from forms and techniques that librarians have traditionally used for the descriptive cataloging of publications. ${ }^{2}$ It might be appropriate and timely to analyze how scholars actually use manuscripts and at what stage in their research. Librarians, and archivists (by default), tend to act as if the user of manuscripts differed in his approach to his material from the user of books and serials. ${ }^{3}$ Experience with referrals

${ }^{2}$ See T. R. Schellenberg, The Management of Archives (Columbia University, 1965) Part I, for a thorough analysis.

${ }^{3}$ See Berner, "Archivists, Librarians, and the $\mathrm{Na}$ tional Union Catalog of Manuscript Collections," American Archivists, July 1964. 
from NUCMC and at the repository level cast doubt upon this view.

It may be well to turn first to the section in the new Anglo-American Rules that applies to "nonbook materials." NUCMC descriptive cataloging rules as enshrined now in the new Anglo-American "Code" unfortunately set in train a misleading line of thought about bibliographical control of manuscript collections.

These rules represent a "technocratic" approach to an organismic problem. They view "cataloging" as separable from the total process of bibliographic control. They lead manuscripts people to believe that "cataloging" can be done directly from the manuscripts themselves, and done effectively. This is merely an extension of the technique that the Code recommends for individual manuscript items-a method modeled upon those used for book cataloging. As such they are an inducement to item description or a variant thereof. Item description, with rare exceptions, is justifiable only after comprehensive control has been already established for the collection as a whole. To attempt item description prior to establishment of broad comprehensive bibliographical controls results in the limiting of access to manuscript groups not yet processed, either because little is known about them, or, as often happens, because unprocessed groups are restricted from use until they are actually processed. When the NUCMC cataloging rules are followed, the temptation-if not the tendency-is for the reporting repository to catalog its own holdings simultaneously and to do so by cataloging directly from the manuscripts themselves rather than from the synopses of the manuscript groups, whether the synopsis be a register, inventory, guide, or similar finding aid. This indeed was the hoped-for result as expressed by Lester $\mathrm{K}$. Born, the first head of the Manuscripts Section for NUCMC, in a letter to the present au- thor dated October 19, 1959, wherein he hoped that “. . . these rules . . . will, presumably, be followed in the future by most repositories that have not already set up elaborate catalogs." The important step preceding that of "cataloging" should be, in the judgment of many, production of a register, guide, or other synopsis that is to be cataloged, not the cataloging of the manuscripts themselves.

A repository, however, need not do "original" cataloging. One of the saving features of the NUCMC reporting system is that reporting can be done in synopsis form with the data sheet. The data sheet is closely analogous to the repository's own "register" or inventory/ guide. By its use of the data reports, NUCMC can legitimately catalog without simultaneously imposing its cataloging system upon the reporting repository. It might therefore be recommended that NUCMC ask for reporting by data sheet alone, thereby escaping the onus for spreading an unproved, if not wrong, bibliographic method across the manuscript and library world. Its cataloging methods appear much too young to be enshrined.

Present practice in fact suggests that the card catalog should be the basic finding aid to the holdings of a manuscript collection. Although the card cata$\log$ is the basic finding aid at most repositories, this is not necessarily good. The card catalog, as a form, simply developed out of a vacuum that existed long before archival techniques were developed. But even after archival methods began to spread, they were long thought to be applicable almost exclusively to public records. And, as evidenced by the strong representation of the archival profession on the Advisory Committee for NUCMC, even the archivists themselves thought they were inapplicable to the management of manuscript collections, for the end result showed little archival influence. So instead of following Dr. 
Born's suggestion that those repositories "... that have not already set up elaborate catalogs. . ." be guided by the NUCMC rules for descriptive cataloging, they might better be urged to consider whether NUCMC rules are applicable at all. It does not follow necessarily that uniformity of end product, which is desirable at the national level of bibliographical control, should be required at the repository level itself. It is perhaps unfortunate that the "Anglo-American Rules" imply that it should be.

Quite the contrary; the inventory/ guide and register, which are basic archival finding aids, should be seriously considered as the basic finding aids for manuscript collections as well, for the kind of records being described are essentially the same: file items or units usually arranged in record series and organic subgroups. There should in turn be cumulative indexes to names, subjects, places, and dates. In recognition that some users approach their materials by dates, there should be a chronological index that enables the researcher to find references by year or period. NUCMC itself would be made more useful with such an index. These indexes would accommodate effectively to the diverse ways in which manuscripts are approached by the researcher. Whether these indexes be in catalog card form, sheet form, or in a form for machine retrieval is less important, for scale will or should largely help to determine form. ${ }^{*}$ In all of this, however, the form which the description will take should

\footnotetext{
+ For a presentation of this method see: Richard C. Berner, "Manuscript Collections and Archives-A Unitary Approach" Library Resources and Technical Services, Spring 1965. Also Robert L. Brubaker, "Archival Principles and the Curator of Manuscripts" in the American Archivist, October 1966. See also Carolyn A. Wallace, "The Southern Historical Collection," in the American Archivist, XXIII (July 1965), 427-36, for a description of methods at the University of North Carolina, one of the most exemplary. For the definitive comprehensive background analysis of library and archival methodologies see: T. R. Schellenberg, The Management of Archives (Columbia University Press, 1965) Part I.
}

not be allowed to influence arrangement of the manuscript groups themselves.

Discussion of "subject grouping" of small and/or miscellaneous units of manuscripts for cataloging purposes reflects another line of library thinking and methodology (NUCMC Information Circular No. 2 revised). One of the unfortunate results of such discussion is to suggest that repositories can validly classify manuscripts by subject. To do so would probably encourage violation of the principle of provenance in due course. It would therefore appear more desirable for the manuscript unit to be reported according to its own integral characteristics or not be reported at all.

It would be well to be guided by the archivists' principle of provenance and its ramifications-keeping papers according to the source that generated themand to extend this rule to reporting as well. It is indeed unfortunate that the Anglo-American Rules include only a slight and misleading reference to "provenance," limiting it to "donor or other source of acquisition" (p. 270). The essence of provenance is the organic origins of the papers themselves; the papers are generated out of activity and reflect that activity. This concept is fundamental to sound practice in manuscripts and archival work and should not be subordinated to a casual note applied only to a description. As a concept it might better have prefaced the section in the Anglo-American Rules which is devoted to manuscripts (pp. 259-71). In this position and with a full statement of its theoretical implications, it would have more properly qualified the recommendations that followed.

A total view of the bibliographical process is needed in dealing with manuscript collections extending through both arrangement and description. "Cataloging," if that term be used, should be restricted to a description based upon 
the finding aids or apparatus of the finding aids, and should not be done or encouraged to be done directly from the manuscripts themselves.

NUCMC's experience with the subject headings problem should make librarians and archivists wary. It started with the Library of Congress subject headings list, which was then abandoned for the wrong reasons, ${ }^{5}$ and is now using the more flexible but relatively uncontrolled topical headings. This area is of great concern to specialists in information retrieval and will be the main concern of a member of the National Archives staff in a forthcoming study being done under a grant from the Council on Library Resources. Strong reservations appear to be warranted about subject headings at this stage. There is too much to be learned before fixing upon a system. Dr. T. R. Schellenberg, for example, suggests using a few broad subject headings corresponding to the main lines of human activity. ${ }^{6}$ Such a system is now being experimented with at the University of Washington. But its system is based on wholly different methodological considerations than those of Dr. Schellenberg; they are based on its own analysis of methods employed by scholars in their approach to manuscripts, recognizing the function of name control.

One important by-product of NUCMC is that it provides or can provide much of the data that is needed for an analysis of the methodologies of those who use manuscript collections. Librarians and archivists may well miss an important opportunity if they do not make the analysis and alter their methods of bibliographical control accordingly.

\footnotetext{
'Dr. Schellenberg's oral criticism was that it was more specific than it could reliably be, and as a result it would mislead researchers into believing that all specific references made did in fact exhaust all leads to the particular subject being sought.

"T. R. Schellenberg "A Nationwide System of Controlling Historical Manuscripts in the United States," in the American Archivist, XXVIII (July 1965), 409-12.
}

Some experienced manuscript curators have found that more than 95 per cent of the inquiries from scholars using NUCMC are for materials by way of personal and corporate names; thereby responding, consciously or not, to the fact that persons, real or corporate, create manuscript and archival materials. Yet there has been little response methodologically to this fact on the part of manuscripts people. And at the more "sophisticated" levels of methodology represented in the April 1967 issue of the American Archivist which was devoted to advanced information retrieval techniques-only one article, that by Russell Smith on the Presidential Papers, stresses the importance of names and name control, and this is a matter largely of historical accident, not design. All others are concerned with minute subject analysis, largely ignoring the main approach that scholars use in approaching manuscript collections. The forthcoming study of information retrieval techniques in this field, being financed by the Council on Library Resources, should take this fact into consideration.

Names and name control are very important and central to the methodology on which a national system of bibliographical control should be constructed. The reason names are so important is that by the time the scholar is ready to use manuscript and archival material he has already associated names of persons and corporate bodies with his particular subject more specifically than can the person who describes the manuscript group. This mental association is structured into the researcher's own methodology. He has done this inevitably in the normal course of reading published sources including newspapers, books, periodicals, government documents, and so on, prior to using manuscript and archival sources. If this be true, then name control should influence the kind of subject control needed, a choice between 
broad clues to the manuscript group or the more subjective but specific and item-keyed technique. NUCMC now provides the chance to make these analyses.

With what has just been said about names it appears justified to recommend that NUCMC entries eliminate names from the contents notes except where they can indicate organic relationships as, for example, names of subgroups that often exist within a given manuscript group, or organizational affiliations that are often reflected in it. They should be in the cumulative index, of course; by conserving space through their elimination from the contents note more names can be entered in the index. The more names, the less arbitrary their se- lection. This too would make it more truly an interphased system wherein the user proceeds from individual name and subject leads successively to more detailed contextual information in NUCMC and then to the repositories themselvesinterphasing without pointless repetition of information as he proceeds through the phases of information retrieval.

Note-Other articles of interest on NUCMC are:

Harriet C. Owsley, "The SAA Workshop on the National Union Catalog of Manuscript Collections," American Archivist, XXVIII (July 1965), 389-97.

William C. Binkley, "A Historian Looks at the NUCMC," American Archivist, XXVIII (July 1965), 399-407.

Robert H. Land, "The NUCMC," American Archivist, July 1954. 